\title{
WEB BASED SYSTEM FOR CHOOSING A STATISTICAL METHOD FOR DATA PROCESSING
}

\author{
Antoaneta Yordanova ${ }^{1}$ \& Marin Yordanov ${ }^{2}$ \\ ${ }^{1}$ Faculty of Mathematics and Informatics, Plovdiv University „Paisii Hilendarski“, Plovdiv \\ Tzar Asen 24, 4000 Downtown area, Plovdiv, Bulgaria, e-mail: tonyjordanoff@gmail.com \\ ${ }^{2}$ Faculty of Technics and Technologies, Trakia University \\ Graf Ignatiev 38, 8600 Yambol, Bulgaria, e-mail: m.iordanovv@gmail.com
}

\begin{abstract}
Choosing a statistical method is essential for obtaining accurate results and interpreting them correctly. Survey of Web based tools, advisory systems in the field of statistics has led to the conclusion that in Bulgaria there are not any created. This necessitates the development of such a tool for Bulgarian consumers. The analysis of the technological tools for building Web-based systems as well as the research of algorithms for choosing of statistical methods determined the idea of creating a Web-based system for choosing a statistical method. This article introduces the developed Webbased system for choosing a statistical method - Webstat.
\end{abstract}

Keywords: Choosing a statistical method, Web-based systems.

\section{INTRODUCTION}

In all the scientific spheres and education, the implementation of statistical methods is of exceptional significance both for the organization of scientific researches, and for practice. The incomplete understanding of the basic statistical methods and the lack of skills of choice of adequate method often leads to difficulties and to implementation of methods, inappropriate for the available data of experiment. The latter may have reflection over the interpretation of the results and to lead to incorrect conclusions. The hypotheses may be rejected even if being true and to be accepted, if they are untrue. On the other hand, even during the projection of the experiment it is necessary to take a decision for what kind of data to be collected in regards of the purpose of the study. This is how the situation is avoided when data is gathered chaotically and after that a method of processing is looked for, so that to prove something not provided initially in the study. Other problems in data usage, particularly data for agricultural researches are given by Georgiev [6] as incorrect planning of the research experiment, lack of knowledge about the standard statistical methods applicable in that sphere and lack of skills to choose the appropriate method, so that to achieve the purpose of the research. These thoughts have directed us to the creation of Web-based statistics system, which to assist during the selection of the adequate statistical methods for data processing without restriction of the implementation sphere.

The purpose of the present work is study of the theoretical and application aspect of Webbased system for selection of statistical methods and a presentation of concrete system assisting the choice of statistical methods.

\section{MATERIAL AND METHOD}

The development of the Internet as communications and work environment changed the characteristics of software and leads to abolishing of accessibility restrictions, of the dependence on operational system and localization. The program applications in the modern IT are defined as two basic types in regards of their accessibility and work environment: locally and Web-based.

IRTTL Vol. 6, No. 2, 2018 ISSN 1314-8788 (print), ISSN 1314-8796 (online), doi: 10.15547/artte.2018.02.009 


\section{ARTTIE $Y$}

Ipplied Researirches in Technics, Technologies ind Eduration

Journal of the Faculty of Technics and Technologies, Trakia University https://sites.google.com/a/trakia-uni.bg/artte/

The Web-based applications are closely connected to Internet without local specialized program. The processes of entering, processing storage and distribution of information are realized in Internet environment. There the technology Client-Server is applied, which provides their basic advantages - easy accessibility from any point globally with the help of Web browser. The specialized machines or software play the role of server and fulfill the demands of the client's programs and under ideal conditions have uptime of 24 hours. This determines one more advantage - constant activity and work in real time. Ability for multiconsumer operation and usage trough different digital devices - laptops, desktops, tablets etc.

\subsection{Web based resources in the field of statistics}

In our modern time the computing machines become more and more powerful, and the statistical program packages are more and more overwhelming and the question rises not so much about the very data processing but more about what statistical method to be chosen.

The procedure of choosing the appropriate (adequate) is a stage of the planning of every scientific experiment. This matter is poorly studied in the Bulgarian scientific literature. The teaching and studying of the discipline "experiment planning" is also rare in the Bulgarian universities.

A disadvantage of the teaching literature in "Statistics", "Biostatistics", "Experiment Planning", is that it is published in small quantities and is not distributed on national scale. In most of the cases it is available only in the respective university libraries or bookshops. This makes difficult the research process of the study of the said sources. A good practice of the recent years is the free online access to lectures, notes, directions of statistics [20], [7]. These are predominantly materials by lectures- professionals in statistics of the math and computer science Saint Kliment Ohridski, and FMI Paisij Hilendarski. Due to the more theoretical focus of the presented scientific material, the question of the method choice is not considered as real problem in the latter materials. However, in the studies of the specialists from the biological, agrarian and medical majors in the spheres of experiment planning biostatistics and psychology, this matter is studied by [5]. No Bulgarian language online accessible procedures, schemes, presentations, video clips and other additional literature on the matter for method choice analogical to the here in after quoted sources in English language are discovered.

How important is the correct choice of the statistical method one can conclude in connection of the many publications regarding statistical errors in scientific publications. Serious concerns are expressed that half of the public works in biology had serious statistical errors [9]. Several thousand publications are studied and even in several of them there was no information of the used statistical methods.

In another research of 513 articles in five magazines with highest rank (Science, Nature, Nature Neuroscience, Neuron, The Journal of Neuroscience) 79 are found, which have used incorrect procedures. [12]

The statistics method choice is a procedure based on consequent reply to several key questions regarding:

- Purpose of the scientific study;

- Number of measured/counted variables;

- Type of the measurement scale of variables;

- Dependence or independence of variables etc.

When comparing the range of the questions and the number of results we have paid attention the diagram of Charle Kufs [10], which gives the biggest number of statistical methods as choice opportunity.

IRTTL Vol. 6, No. 2, 2018 ISSN 1314-8788 (print), ISSN 1314-8796 (online), doi: 10.15547/artte.2018.02.009 


\section{ARTTEY $Y$}

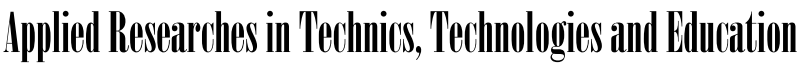

Journal of the Faculty of Technics and Technologies, Trakia University https://sites.google.com/a/trakia-uni.bg/artte/

This scheme is preferred because it contains:

- Most key questions (five)

- Gives the most statistical techniques for data processing

- Statistical methods are also included, which are not covered by the standard university programs of natural science.

The provided statistical aims are five - description, classification, comparison, prediction and explanation and are studied in regards of each key question.

The difference of this scheme and the others is that it does not start with the purpose of the statistical study, which is more logical also a stage of experiment planning.

No scheme with more than five questions and including better variety of statistical technics and aims have been discovered.

\subsection{University training sites}

After the sites of the above mentioned statistical packages the most informative are those of the universities and more particularly those of the ones who have trainings in the sphere of statistics. The academic programs of the high-ranking universities are online accessible and it is visible that the issue for statistical method choice is included. This theme is visualized in the following for ways:

- list of the key questions for method choice [5];

- diagram with key issues [11];

- interactive diagram with key issues related to the table containing statistical techniques [13];

- table containing statistical techniques and link to examples to four major statistical packages [19].

On the sites of the universities one can find accessible and free of charge resources as student's books and statistics manuals.

\subsection{Statistical packages for data processing, manuals}

Today the use of computers is a must, in order to analyze and organize a considerable quantity of data and to perform statistical analysis with them. Due to the fact that computer can process enormous quantity of data the statistics professionals dedicate less time for computations and this manner thereby they focus on the choice of the appropriate research design, model and statistical procedure.

In the statistical packages there is no opportunity software automatically to chose the most appropriate method for data processing. For user's assistance the packages include advise modules and manuals, as for example StatSoft Statistica and IBM SPSS. A disadvantage is however that the said packages are paid. The advisor method choice as well as the work manual with Statistica are accessible via web. [17] There is such available also for SPSS in the Internet. [8]

\subsection{Online statistical processing}

After the search for online statistical calculators in the Internet we shall pay attention on the following three which further we include on the project of the web site.

1. The site Statistics Calculators offers online calculators for seven statistical computation processes. It is accessible in the English language [4].

IRTTE Vol. 6, No. 2, 2018 ISSN 1314-8788 (print), ISSN 1314-8796 (online), doi: 10.15547/artte.2018.02.009 


\section{ART'TE $Y^{2}$ \\ Ipplied Researldhes in Technics, Technologies ind Bductition \\ Journal of the Faculty of Technics and Technologies, Trakia University \\ https://sites.google.com/a/trakia-uni.bg/artte/}

The calculators operate with the user's data, but if the latter is in a difficult situation he is given examples. In the exit results the formulas are seen which have been proposed in the computations. A disadvantage of the web site is however that it does not propose complex statistical methods.

2. On the site Social Science Statistics [16] there are statistical calculators which cover more sphere of statistical calculations. The website is in English. It is defined as intuitive calculator easy for usage and includes methods applicable in the social sciences. The user enters parameter values manually via the keyboard, no importing from file is allowed. The calculations are online performed and the result indicates statistical credibility and the formulas used.

An advantage of that website is that it has a subpage, dedicated to the method choice or advisory procedure. It includes the questions raising for the types of the alternatives, their number and the connections between them after which directs to the appropriate calculator in the website.

3. The website Simple Interactive Statistical Analysis [14] offers wide range of statistical online calculations, grouped in procedures for data, tables, statistical distributions, etc. in English language.

And advantage of that website is flexibility in the choice of final results.

An interesting resource is a presentation available in the Internet which assist the method choice [2]. It could be downloaded for free. Its main aim is to assist researchers and students in the sphere of Orthodontology in the choice of appropriate statistical test for study of one variable. It is interactive and paced on the real intentions of the researcher.

\subsection{Systems assisting statistical method choice}

In the process of the study of the web-based systems for advises in statistics no such were discovered in Bulgaria. Only three were found analogical to the designed system in English language. References to them are included in the website sections about the method.

1. Selecting Statistics - developed in the Cornell university. The system puts forward five questions after the reply of the said questions a list of the recommended methods is given.

2. Choosing a statistical test - a statistical web page and advises are reduced to a table with column about the types of aims of the processing and the types of variables. It is developed in conformity with a text book of the Oxford university from 1995.

3. The decision tree for statistics - this system is created in 2014 based on a manual for statistics work of the institute for social studies unto University of Michigan. It raises the same questions as in the website Selecting Statistics.

4. Don't panic! - this is a paid system assisting statistical method choice which targets natural science.

\subsection{Video resources}

The biggest source for video resource sharing is YouTube where StatSoft and IBM SPSS statistics have their own video channels. The video resources for statistical method choice can be the following types

- Clips following the choice scheme [3];

- Clips training operation with a certain specialized software [15];

- School clips related to main statistical packages [18]. 

https://sites.google.com/a/trakia-uni.bg/artte/

\section{RESULTS}

\subsection{Conceptual model of Web-based system for statistical method choice}

Statistics is powerful instrument and if we know how to use it, it shall facilitate our work and make it more efficient more secure more consistent and quicker.

The ignoring of the statistical methods significance and the choice of appropriate methods for the respective experiment may lead to erroneous interpretation and decisions.

The incomplete study of the major statistical methods and the lack of skills of choice of adequate methods, most often leads to difficulties and to the implementation of methods inappropriate for the data available.

If we are not prepared, we need advisor. The web site could serve are such, to orientate user how to think what types of questions to raise before using statistical methods.

Major questions which this website rises are:

1. How many variables do you have?

One, more than one or too many. Because in all these tree cases are not applied the same methods.

2. What is your statistical aim?

- Description;

- Classification;

- Comparison;

- Prediction;

- Explanation.

The aim determines how data should be processed, so that to accomplish the required new knowledge for objects.

3. With what scale your variables are measured?

The scale determines concrete methods, which can be applied because it is not the same whether these shall be figures in a certain interval or degrees, codes and final number of categories and groups.

4. Are there dependent(independent) variables in your data?

For those two types variables (depending and independent) different methods are applied for description, comparison and classification. Even if those methods carry one and the same name they use different mathematical formula in both cases.

Those for questions must have answer before we plan statistical analysis.

5. Are the dependent variables autocorrelated?

Whether they depend on time and place. The dependent variables are measured at a certain place or in a certain time in a certain type of consequence. Depending on the answers of the users the website gives advise which statistical methods are appropriate for the study.

For the realization in the website the above described model for decision taking of statistical method choice is being chosen. [10]

After the analysis of his work the following conceptual module is formulated:

- Key elements - question, variable, aim and method. (Figure.1);

- Characteristics of variables - number, measurement scales and dependences;

- Aims of research - description, classification, comparison, prediction and explanation;

- Methods - results from characteristics of variables and aims of research.

The scheme of the tree for statistical method choice decisions is used as basis or fundament on which the logics of the realized website is built. [10] 


\section{IRTIL $<>$}

Ipplied Ressearlohes in Teednicis, Technologies and Bductation Journal of the Faculty of Technics and Technologies, Trakia University https://sites.google.com/a/trakia-uni.bg/artte/

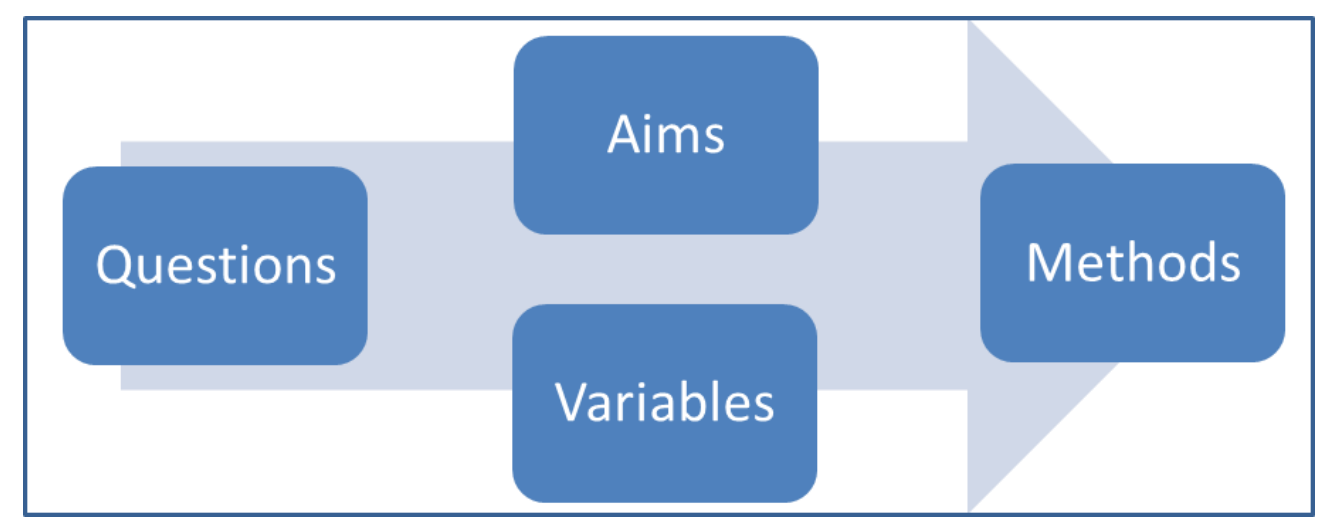

Figure 1. Key elements of the model

\subsection{Choice of environment for system development}

After a study preformed of the instruments for building of web-based system the plain HTML code is chosen. It is breached with more difficulties and it supposes authorized access to the server for realization of code changes.

This conclusion as well as the understanding that the use of appropriate template for web page would facilitate and accelerate the development are the reason to choose this approach.

A research has been realized of the different template systems as a result of which the template HTML 919 Free Web site [1]. It is distributed in conformity with a specific authors license based on GNU/GPL.

The used DTD in the case with that template is XHTML 1.0 Transitional. The template contains five basic pages, applies CSS for the formatting of the pages and has scripting of one of the pages via Java Script. Major colors are blue, red and yellow. The contrasting is light to dark on light letters on dark background.

\subsection{Block scheme of the algorithm for system operation}

The operation of the system is determined by the algorithm for statistical method choice and follows the decision tree above mentioned. The presentation of the process for systematical method choice as a block scheme is given on Figure 2.

It is provided as a cycle for application of a method for reduction of the number of variables until becoming one or more than one, but not too many. We haven't included block for the end of the algorithm most intentionally as it could perform the work with the website multiple times. There is no exit marked as "NO" in the logical blocks, which represent the aims as it is possible to chose more than one aim periodically. Their choice is not alternative, which is not valid when working with autocorrelational variables. There are two possible alternative dependences on the place or time. Since they don't depend on the place they have to depend on time and that is why a block for operation and action is included. The measurement scale is integrated in the description of the chosen methods and because of that it is not given separately for discrete and uninterrupted scales. 


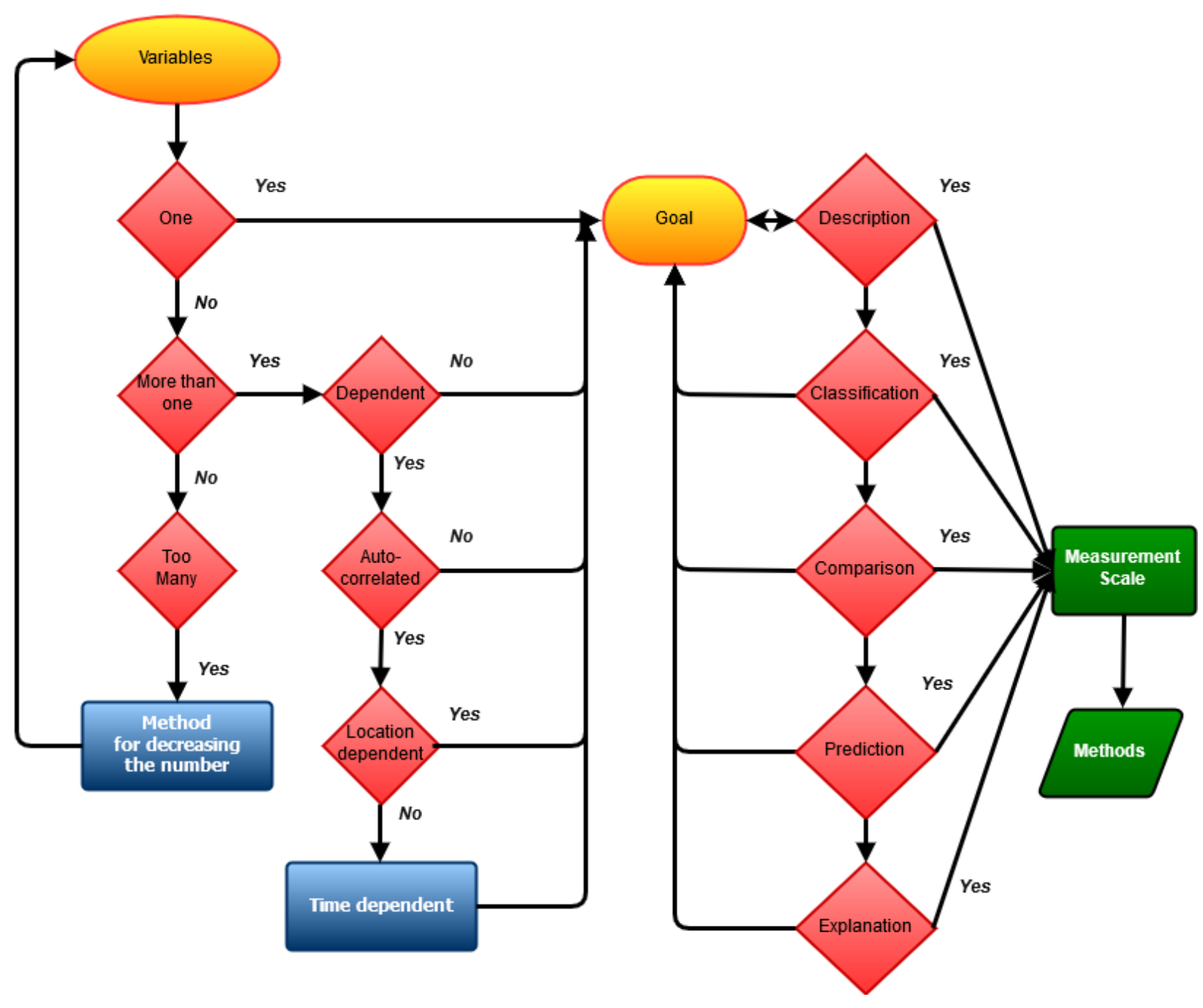

Figure 2. Block scheme for algorithm statistical method choice

\subsection{Realization of the Web-based system Webstat}

The created system, consulting the statistical method choice is located on URL address http://webstat.uni-sz.bg. It is published on a server of the Trakia University. It operates on a virtual machine using subdomain of the University one.

On Figure 3 the initial page of the website is represented.

The Web-based system is built on the base of the template above mentioned which is adapted and extended, so that to realize the chosen decision tree. It could be found on the initial page of the website. Through the choice of answers to the questions raised one can move to the respective subpages. On the right side of the page there is a dictionary of statistical terminology. When the questions have finished appropriate statistical methods for processing are numerated.

The website is comprised by seven main subpages - about method, data, resources, links, dictionary and references. 


\section{AR'IIE}

Ipplied Resererrches in Technics, Technologies ind Bducation Journal of the Faculty of Technics and Technologies, Trakia University https://sites.google.com/a/trakia-uni.bg/artte/

\section{w 35 rtif Избор на подходящ статистически метод}

НАЧАЛО ЗАМЕТОАА ААННИ РЕСУРСИ ВРВЗКИ РЕЧНИК ИЗТОЧНИЦИ

Това е съветваща система, която има за цел да помогне при избора на подходящ статистически

метод за обработка на Вашите данни.

Вземането на решение е съпроводено с това да отговорите коректно на поредица от въпроси. 3 а приложеното дьрво на решенията или за метода на избор, който е реализиран в тази система, можете да прочетете в раздела за метода.

Започнете с отговора на първия въпрос:

Колко променливи имате?

ЕАНА ПОВЕЧЕ ОT ЕАНА ТВЪРДЕ MHOГО

ПРОМЕНЛИВА ПРОМЕНЛИВА ПРОМЕНЛИВИ

За връзка

m.iordanovw@email.com

Марин Йорданов

Figure 3. Front page of the Web-based system

In the subpage About method there is a brief description of the five key questions on the grounds of which the respective system is built.

In Data there are links to the pages of the National Institute of Statistics, Gapminder World, Gallup International. There are also links to other statistical institutes. This done with the aim in case of impossibility to find data for processing.

In Resources which are divided in sub manuals - Manuals, Packages, online Packages and Training. There are links to statistical calculators. The official websites of Statistica [17], IBM SPSS Statistics, SAS/Stat and other training materials using the set software.

In Links there are training video materials in statistics.

In Dictionary there is short dictionary of the major statistical terminology.

In References the major used sources from the Interned for the Web site development are cited.

IRTTE Vol. 6, No. 2, 2018 ISSN 1314-8788 (print), ISSN 1314-8796 (online), doi: 10.15547/artte.2018.02.009 


\section{ARTTIE $Y$}

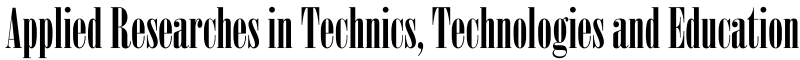

Journal of the Faculty of Technics and Technologies, Trakia University https://sites.google.com/a/trakia-uni.bg/artte/

\subsection{Poll}

In order to get feedback from the opinion and assessment of academic users of the Web system for choosing a statistical method, a poll is created via Google Forms available at: https://goo.gl/forms/id6rSj9NpxP4Yd9z1

The questions in the poll are divided in two groups. Group I establishes the position of the interviewee and the second his experience in statistics. Group II establishes the judgment of the interviewed about the site and the published material in it. The following specific questions are included:

1. You are: Student, PhD student or Lecturer.

2. Do you have experience in the field of statistics?

3. Do you agree, that this site is advisory system for choosing a statistical method?

4. Do you accept the five key questions in the method as clear and understandable?

5. Is there enough additional material in the system to expand your knowledge of statistics?

6. Would you use this site in your future research work?

7. Is it helpful the presence of short explanations about the methods?

8. Are the resources offered in the Website sufficient?

Possible answers to the questions is a set of affirmations: yes; Closer to yes; neutral (I cannot judge); rather not; no.

\section{CONCLUSION}

As a result of the study of the tools for Web-based system building a correct approach is chose trough the usage of the template system. This ensured comparatively easy, quick and effective work on its creation. This approach is characterized with adaptivity and flexibility, providing the possibility of adding new elements, styles and scripts.

The inquiry made convinces us that the creation of the advisory system for the statistical method choice in the Bulgarian language is very useful for the students, post graduates and lecturers. This obliges us to maintain the system for the future to update it and improve it. Due to the significance of the statistical method choice during realization of any experiment it is recommendable in the courses of statistics and statistical methods unto Trakia University to be included a theme with that content. The developed web site can be useful.

\section{REFERENCES}

[1] ATN. (2016). HTML 919 Free Website Template. [Online]. Available: www.alltemplateneeds.com/ [2016-08-17].

[2] Normando D. et al. (2010). A PowerPoint-based guide to assist in choosing the suitable statistical test. Dental Press J. Orthod. Vol. 15, No. 1, 2010.

[3] Goldstein E. (2015) Choosing a Statistical Test [Online] Available: https://www.youtube.com/watch?v=UaptUhOushw [2015-05-15].

[4] Freemathhelp. (2017). Math portal org. Online calculators. [Online]. Available: http://www.mathportal.org/calculators/statistics-calculator/ [2017].

[5] Ganeva Z. (2016). To rediscover statistics with IBM SPSS Statistics. unknown: Elestra Print, ISBN 978-619-7292-01-5, 2016.

[6] Georgiev V. (2004). Creation of models and software applicable to the processing of agricultural research data. Plovdiv: Dissertation, 2004. P. 5.

[7] Gocheva S. (2010). Business Statistics with SPSS. [Online] Available: http://www.fmiplovdiv.org/evlm/DBbg/probstatmenu/index.htm [2010]. 


\section{ART'TE $Y$}

Ipplied Researches in Technics, Technologies ind Bductition

Journal of the Faculty of Technics and Technologies, Trakia University https://sites.google.com/a/trakia-uni.bg/artte/

[8] IBM. IBM Knowledge Center. [Online] Available: https://www.ibm.com/support/knowledgecenter/SSLVMB_22.0.0/com.ibm.spss.statistics. help/spss/base/overvw_auto_0.htm.

[9] InfluentialPoints.com. (2012). Statistical Mistakes in Research. Use and misuse of statistics in biology. [Online] Available: http://influentialpoints.com/Training/statistical_mistakes_in_research_use_and_misuse _ of_statistics_in_biology.htm [2012].

[10] Kufs Charlie. (2011). Stats with Cats: The Domesticated Guide to Statistics, Models, Graphs, and Other Breeds of Data Analysis. Tucson, Arizona: Wheatmark, ISBN-13: 978-1604944723, 2011.

[11] University of Minnesota. (2017). Types of Statistical Tests. [Online] Available: https://cyfar.org/types-statistical-tests [2017].

[12] Nieuwenhuis et al. (2011). Nature Neuroscience 14. 2011.

[13] PennState Eberly College of Science. (2017). STAT 500. The Pennsylvania State University. [Online] Available: https://onlinecourses.science.psu.edu/stat500/node/67 [2017].

[14] SISA. (2017). Simple Interactive Statistical Analysis. Simple Interactive Statistical Analysis. [Online] Available: http://www.quantitativeskills.com/sisa/ [2017].

[15] Statistics Learning Centre. Choosing which statistical test to use - statistics help [Online] Available: https://www.youtube.com/watch?v=rullUANOU3w [2012-01-31].

[16] Statistics, Social Science. (2017). Social Science Statistics. [Online] Available: http://www.socscistatistics.com/tests/Default.aspx [2017].

[17] StatSoft. (2016). Statistica Electronic Manual. [Online] Available: http://documentation.statsoft.com/STATISTICAHelp.aspx?path=common/AboutSTATIST ICA/ElectronicManuallndex [2016].

[18] TheRMUoHP Biostatistics Resource Channel. (2013). How to Use SPSS: Choosing the Appropriate Statistical Test [Online] Available: https://www.youtube.com/watch?v=DcS6_I63PHs [2013-09-05].

[19] UCLA. (2017.) Choosing the Correct Statistical Test in SAS, Stata, SPSS and R. [Online] Available: http://stats.idre.ucla.edu/other/mult-pkg/whatstat/.

[20\} Vandev Dimitar. (2002). Notes on Probability Theory. [Online] Available: https://store.fmi.uni-sofia.bg/fmi/statist/personal/vandev/lectures/prob/Prob.htm [2002].

IRTTIV Vol. 6, No. 2, 2018 ISSN 1314-8788 (print), ISSN 1314-8796 (online), doi: 10.15547/artte.2018.02.009 